\title{
Catalytic and functional aspects of different isozymes of glycolate oxidase in rice
}

\author{
Zhisheng Zhang ${ }^{1}$, Xiangyang $\mathrm{Li}^{2}$, Lili Cui ${ }^{2}$, Shuan Meng ${ }^{1}$, Nenghui Ye ${ }^{1}$ and Xinxiang Peng ${ }^{2^{*}}$
}

\begin{abstract}
Background: Glycolate oxidase (GLO) is a key enzyme for photorespiration in plants. There are four GLO genes encoding and forming different isozymes in rice, but their functional differences are not well understood. In this study, enzymatic and physiological characteristics of the GLO isozymes were comparatively analyzed.

Results: When expressed heterologously in yeast, GLO1, GLO4 and GLO1 + 4 showed the highest activities and lowest $K_{m}$ for glycolate as substrate, whereas GLO3 displayed high activities and affinities for both glycolate and L-lactate, and GLO5 was catalytically inactive with all substrates tested. To further reveal the physiological role of each GLO isozyme in plants, various GLO genetically modified rice lines were generated and functionally analyzed. GLO activity was significantly increased both in GLO1 and GLO4 overexpression lines. Nevertheless, when either GLO1 or GLO4 was knocked out, the activity was suppressed much more significantly in GLO1 knockout lines than in GLO4 knockout lines, and both knockout mutants exhibited obvious dwarfism phenotypes. Among GLO3 and GLO5 overexpression lines and RNAi lines, only GLO3 overexpression lines showed significantly increased L-lactate-oxidizing activity but no other noticeable phenotype changes.
\end{abstract}

Conclusions: These results indicate that rice GLO isozymes have distinct enzymatic characteristics, and they may have different physiological functions in rice.

Keywords: Glycolate oxidase isozymes, Enzymatic characteristics, Physiological functions, Rice (Oryza sativa)

\section{Background}

Glycolate oxidase (GLO, EC 1.1.3.15) is an important peroxisomal FMN-dependent oxidase involved in photorespiration. Plant photorespiration begins with the oxygenating reaction of ribulose 1, 5-bisphosphate carboxylase-oxygenase (Rubisco) in chloroplasts. This process produces a toxic intermediate metabolite phosphoglycolate (2-PG), which is further converted to glycolate by 2-PG phosphatase (PGP). Glycolate is transferred to peroxisomes and oxidized into glyoxylate by GLO with equimolar amount of hydrogen peroxide $\left(\mathrm{H}_{2} \mathrm{O}_{2}\right)$ released [1-3]. In addition to its metabolic function in photorespiration, GLO has been reported to play roles in plant photosynthetic regulation and stress resistance. Suppression of GLO leads to glyoxylate accumulation and inhibits photosynthesis, while overexpressing GLO

\footnotetext{
* Correspondence: xpeng@scau.edu.cn

${ }^{2}$ State Key Laboratory for Conservation and Utilization of Subtropical

Agro-bioresources, College of Life Sciences, South China Agricultural

University, Guangzhou, Guangdong 510642, China

Full list of author information is available at the end of the article
}

confers improved photosynthesis under high light and high temperature in rice $[4,5]$. GLO has been significantly induced in cowpea, tobacco and pea under drought stress [6-8], while in rice and barley, GLO was induced notably by pathogen infection [9-11]. Furthermore, because of the high metabolite flux of photorespiration, about $70 \%$ of the total $\mathrm{H}_{2} \mathrm{O}_{2}$ in $\mathrm{C}_{3}$ plants comes from the oxidation of glycolate as catalyzed by GLO, and this value could be even higher under some stress conditions such as drought and high temperature [3, 12-14]. Therefore, GLO may also play an important role in plant $\mathrm{H}_{2} \mathrm{O}_{2}$-related pathways.

The sequencing of Arabidopsis thaliana, Nicotiana benthamiana and rice revealed that GLO are encoded by a gene family in these plant species $[15,16]$. Moreover, GLO isozymes have been observed in several plant species such as Arabidopsis thaliana, maize, and spinach [16-19]. The expressions of isozymes are usually tissue-specific, which may satisfy metabolic behavior of the cells in which each isozyme is expressed [20,21]. For example, the Arabidopsis 1-Amino-cyclopropane-1-carboxylate synthase 
isozymes are biochemically distinct, have tissue-specific expression, and function in different cellular environments for $\mathrm{C}_{2} \mathrm{H}_{4}$ synthesis [21]. The GLO isozymes have been reported to show tissue-specific expression in maize and Arabidopsis (e.g., there are two different GLO isozymes exist in the bundle sheath and mesophyll tissues of maize leaves) $[17,22]$, while the enzymatic and physiological characteristics of their isozymes have not been comparatively studied. It is not well understood why there are different tissue-specific GLO isozymes in these plant species. In addition, GLO isozymes are related with resistances to various stresses, wherein each GLO isozyme may perform different functions. Rojas et al. (2012) found that each Arabidopsis GLO isozyme could play different roles in the $\mathrm{H}_{2} \mathrm{O}_{2}$ signal transduction to induce defense responses during the nonhost resistance of Arabidopsis thaliana [16]. Arabidopsis GOX1 and GOX2 have been reported to perform different functions in the oxidative stress-related cell death [23]. Accordingly, the potential tissue- or environment-specific expression and enzymatic diversity of rice GLO isozymes would be relevant to the distinct physiological function of each GLO isozyme during various biological processes.

A total of four $G L O$ genes have been identified in rice genome (i. e., Os03g0786100, Os04g0623500, Os07g0152900 and Os07g0616500, encoding OsGLO1, OsGLO3, OsGLO4 and OsGLO5), each of which has a peroxisomal targeting signal, PTS1 [24]. In this study, we comparatively investigated the enzymatic characteristics of each GLO isozyme, and furthermore, different genetically modified rice lines of these GLO genes were generated and analyzed for functionality. Our results demonstrate that rice GLO isozymes have distinct enzymatic characteristics, and their physiological functions are nonredundant in rice.

\section{Results}

\section{Transcriptional expression patterns of GLO genes and} their responses to stresses

The rice genome contains four $G L O$ genes located on three different chromosomes [15], both the mRNA sequences and polypeptides of these four GLO genes are highly similar (Additional file 1). Our previous transcriptional analyses have shown that GLO1 and GLO4 were predominantly expressed in leaves, while GLO3 and GLO5 were mainly expressed in roots $[15,24]$. In this study, we further noticed that GLO1 and GLO4 were abundantly expressed in leaves and leaf sheaths, and moderately expressed in stems and husks. GLO3 was primarily expressed in stems and leaf sheaths, and GLO5 was only slightly expressed in leaves (Fig. 1a). Furthermore, transcription profiles of $G L O$ genes were analyzed for leaves at different growth stages. The expression of GLO1 increased about $65-75 \%$ in the booting and heading stages but not in other developmental periods, while GLO4 only showed a $35-40 \%$ increase in the booting and heading stages (Fig. 1b). The expression levels of GLO3 and GLO5 were very low in rice leaves throughout all developmental periods (Fig. 1b).

Because GLO is reported to be involved in stress resistance in plants [6-11], we investigated responses of different GLO gene members to various stresses here (PEG 6000, 10\%; NaCl, $100 \mathrm{mM}$; ABA, $10 \mu \mathrm{M} ; \mathrm{H}_{2} \mathrm{O}_{2}, 5 \mathrm{mM}$; $\mathrm{AlCl}_{3}, 2 \mathrm{mM}$; CK, Control group). The results showed that GLO1 transcripts increased by $60 \%$ under PEG treatment, but decreased about $35-40 \%$ under other treatments such as $\mathrm{NaCl}$ and $\mathrm{ABA}$ treatments (Fig. 1c). GLO4 expression showed a $35 \%$ increase under $\mathrm{NaCl}$ treatment, but was suppressed by $25-40 \%$ under $\mathrm{ABA}, \mathrm{H}_{2} \mathrm{O}_{2}$ and $\mathrm{AlCl}_{3}$ treatments (Fig. 1c). Elevated expression level of GLO3 was observed under all treatments, the expression of GLO5 was also increased under these treatments, except for the $\mathrm{AlCl}_{3}$ treatment (Fig. 1c). Meanwhile, GLO activities were correspondingly assayed for the above samples. Inconsistent with the changes in GLO gene expression, the GLO activity only increased $5-8 \%$ under the $\mathrm{PEG}, \mathrm{NaCl}$ and $\mathrm{H}_{2} \mathrm{O}_{2}$ treatments (Fig. 1d).

\section{Enzymatic differences of GLO isozymes}

Enzymatic characteristics of the GLO isozymes in plants are seldom investigated. Previous research found that there are three types of GLO isozymes present in rice leaves, including two that are homo-oligomers composed of either GLO1 or GLO4 subunits, and the others are hetero-oligomers composed of interacted GLO1 and GLO4 subunits [24]. Here the kinetic properties of rice GLO isozymes were comparatively analyzed. A $6 \times$ Histag was fused to the N-terminus of each GLO and expressed in the yeast Saccharomyces cerevisiae, since it has been proved that the $\mathrm{N}$-terminal His-tag rarely influences the properties of the fused protein [25]. Yeast cell lysates were prepared using acid-washed glass beads, and the western blot analyses showed that all GLO isozymes could be heterologously expressed in S.cerevisiae (Fig. 2a). Substrate screens using crude enzyme revealed that GLO1, GLO4 and GLO1 + 4 displayed the highest activity with glycolate as substrate, and showed appreciably high activity on glycerate and less activity on Llactate and glyoxylate (Fig. 2b). In contrast, GLO3 showed the highest activity on L-lactate, and then on glycolate and glycerate, respectively (Fig. 2b). GLO5 was completely inactive to all substrates tested. Each GLO isozyme was further purified from the yeast crude extraction by immobilized metal-affinity chromatography. SDS-PAGE analysis, which guarantees purity for each isozyme, showed an identical subunit molecular weight of about $40 \mathrm{kDa}$ for various isozymes (Fig. 2c). A preliminary analysis showed that the optimum $\mathrm{pH}$ of 7.8 was 

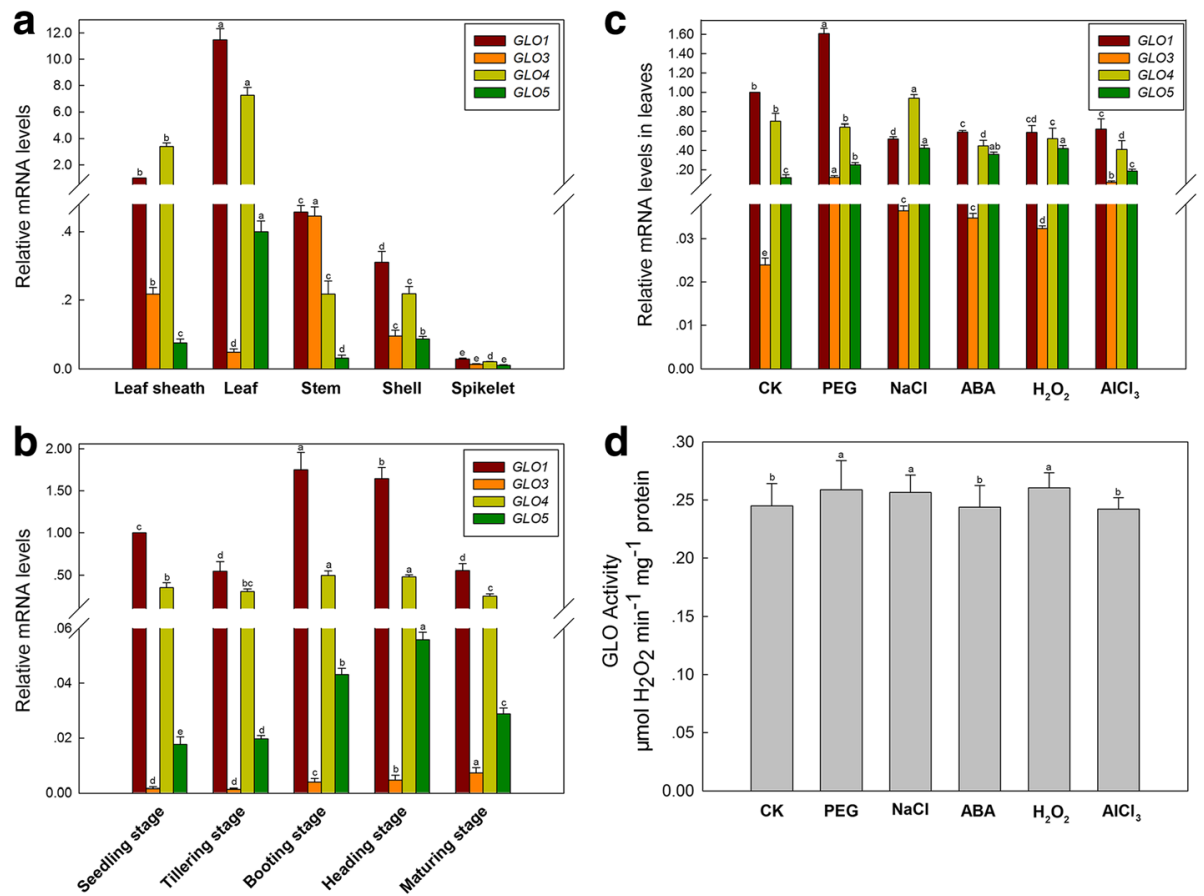

Fig. 1 Expression patterns of GLO genes and their response to stresses in rice. a Relative mRNA levels in different leaf tissues were graphed based on the GLO1 mRNA level in leaf sheath as 1. b Relative mRNA levels at different developmental stages were graphed based on the GLO1 mRNA level in seedling stage as 1. c mRNA transcriptional levels of GLO genes in response to various stress treatments for 2 days (PEG 6000, 10\%; NaCl, $100 \mathrm{mM} ; \mathrm{ABA}, 10 \mu \mathrm{M} ; \mathrm{H}_{2} \mathrm{O}_{2}, 5 \mathrm{mM} ; \mathrm{AlCl}_{3}, 2 \mathrm{mM} ; \mathrm{CK}$, Control group). Relative mRNA levels were graphed based on the GLO1 mRNA level in CK as 1. $\mathbf{d}$ GLO activities in response to various stress treatments (the same samples as in Fig.1c). Values are means \pm SD $(n=3)$. Means denoted by the same letter did not significantly differ at $P<0.05$ according to Duncan's multiple range tests

identical for all GLO isozymes (Additional file 2), and the optimum temperature for GLO1, GLO4 and $\mathrm{GLO} 1+4$ was $42{ }^{\circ} \mathrm{C}$, while the optimum temperature of GLO3 was $47^{\circ} \mathrm{C}$ (Additional file 2).

The kinetic studies were performed at $30{ }^{\circ} \mathrm{C}$ and $\mathrm{pH} 7.8$. GLO1, GLO4 and GLO1 + 4 have the highest affinity for glycolate, with $K_{m \text { (glycolate) }}$ values of $0.499 \mathrm{mM}, 0.613 \mathrm{mM}$ and $0.423 \mathrm{mM}$, respectively (Table 1 ), and the $V_{\max (\text { glycolate) }}$ values of GLO1 + 4 and GLO1 were higher than that of GLO4 (Additional file 3). The affinities of GLO1, GLO4 and GLO1 + 4 for glyoxylate, L-lactate and glycerate were much lower than for glycolate (Table 1). GLO3 also exhibited highest affinity to glycolate, meanwhile, it showed a high affinity to L-lactate, with $K_{m}$ values of $0.470 \mathrm{mM}$ and $1.104 \mathrm{mM}$, respectively (Table 1 ). Oxalate is prevalent in the plant kingdom [26], and is a competitive inhibitor of GLO [27]. Here $K_{i}$ values for oxalate were detected to range from 4.572 to $6.337 \mathrm{mM}$ when using glycolate as substrate (Table 2). Oxalate could more strongly inhibit glyoxylate-oxidizing activity of each GLO isozyme, with $K_{i}$ values between 1.887 and $3.018 \mathrm{mM}$ (Table 2).

\section{Functional analysis of GLO isozymes}

As described above, rice GLO isozymes have distinct enzymatic properties. It is more interesting to know whether these isozymes may play distinct physiological roles in plants. As such, each of the 4 isozymes was overexpressed in rice to determine their contribution to the glycolate metabolism. As shown in Additional file 4, each GLO gene was up-regulated as expected at the mRNA level in the corresponding transgenic line. Overexpression of GLO1 and GLO4 increased GLO activity by $110 \%$ and $65 \%$ in rice leaves, respectively. However, overexpression of GLO3 increased GLO activity by only about 12\% (Fig. 3a) but increased the L-lactate-oxidizing activity by more than $140 \%$ (Fig. 3a). Overexpression of GLO5 had no effect on GLO activity, consistent with the result of enzymatic assay. In addition, both GLO3 and GLO5 were silenced by RNAi (Additional file 4), GLO1 and GLO4 were knocked out using pYLCRISPR/Cas9P ubi system (Additional file 4). In leaves of GLO1 and GLO4 knockout lines, GLO activity was decreased by about $65 \%$ and $20 \%$, respectively, while suppression of GLO3 and GLO5 had no effect (Fig. 3a). The GLO isozymes zymogram analysis of different GLO genetically modified rice lines verified that GLO1 and GLO4 were completely knocked out in the corresponding transgenic lines (Fig. 3b), further supporting our previous results [24]. In contrast, suppression of GLO3 and GLO5 did not alter GLO isozyme patterns (Fig. 3c), implying that in leaves of wild rice plants 


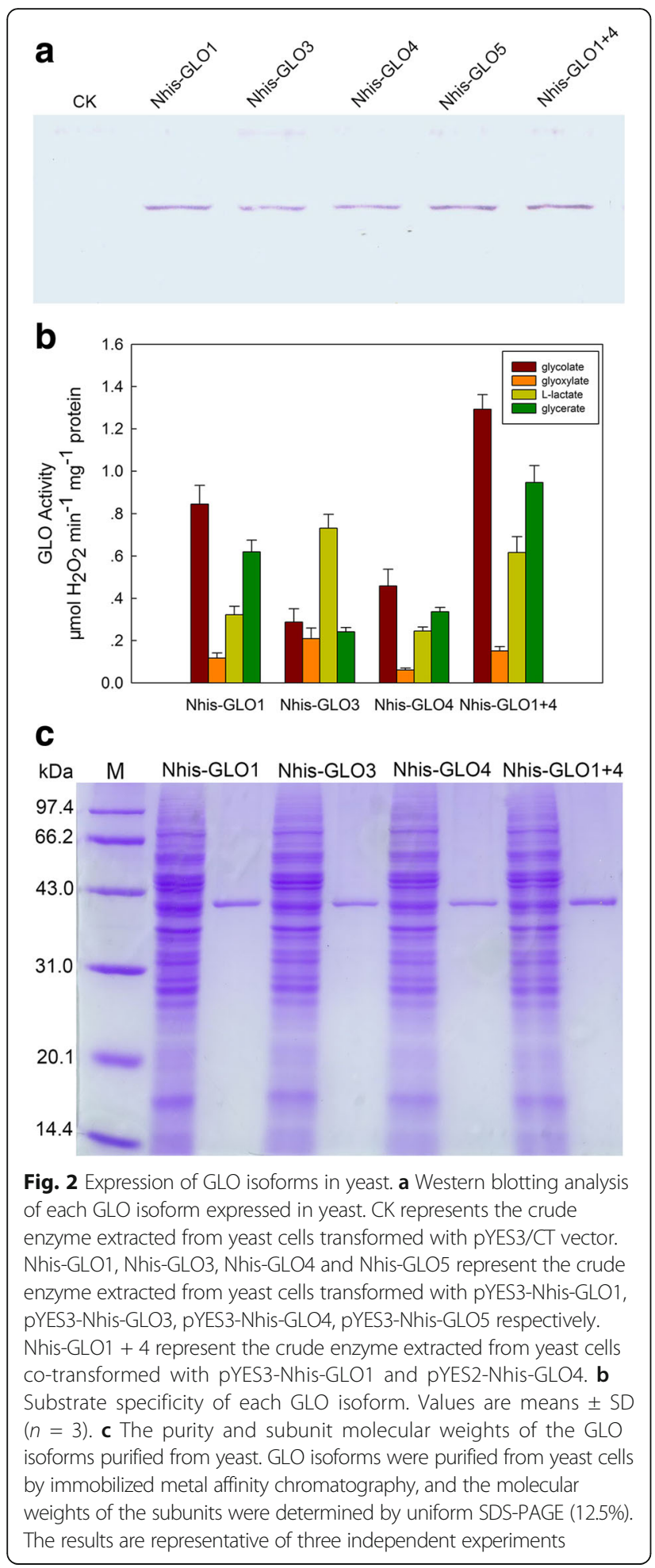

(WT), GLO3 and GLO5 may have not contributed to GLO activities. Consistent with changes in GLO activities as addressed above, phenotypes were not obviously altered in all the GLO3 and GLO5 up-regulated or down-regulated transgenic lines (Fig. 4). However, similar to our previous observations [5], the rice lines with GLO activities suppressed displayed dwarfism phenotype (data not shown), and reduced $\mathrm{H}_{2} \mathrm{O}_{2}$ content was also detected in these rice lines (Additional file 5). However, it was noticed that GLO3 had high activity on L-lactate, meaning that it might participate in the L-lactate metabolism in rice, particularly in the roots (Fig. 2b; Table 1). So we tested if GLO3 contributed to L-lactate tolerance as recently reported by Engqvist et al. (2015). As shown in Additional file 6, the phenotype of GLO3 overexpression and RNAi lines were not different from that of WT plants under lactate treatment, though lactate-oxidizing activity was markedly increased in both leaves and roots of the overexpression lines (Fig. 3a; Additional file 7).

\section{Discussion}

Members of a gene family can have different tissue-, development- or environment-specific expression patterns. Using the GLO gene family that is present in the rice genome [15, 24], we show that the four rice $G L O$ genes are differently expressed in various tissues and developmental stages of the rice plant (Fig. 1a and b), as well as in response to stresses (Fig. 1c). Our findings suggest that the physiological roles of these GLO genes are not redundant, however, the exact biological significance of the rice GLO gene family needs further investigation.

Generally speaking, gene family members that have different expression patterns would encode various isozymes with diverse enzymatic characteristics and physiological roles [21, 28]. In plants, GLO was first purified from spinach $[29,30]$, the primary structure of spinach GLO (SpGLO) was identified by peptide sequencing, which contains only one uniform peptide [31], and its $K_{m}$ for glycolate was detected to be $0.38 \mathrm{mM}$ [32]. GLO was also isolated from Parthenium hysterophorus and Pisum sativum, which both consisted of two different peptides. The $K_{m \text { (glycolate })}$ of the Parthenium hysterophorus GLO is $0.2 \mathrm{mM}$ and that of the Pisum sativum GLO is $0.3 \mathrm{mM}$ [33]. However, the enzymatic characteristics of each GLO isozyme in plants are seldom comparatively analyzed. Arabidopsis contains five GLO members, i. e. GOX1, GOX2, GOX3, HAOX1 and HAOX2 [4, 34], only GOX1, GOX2 and GOX3 have been heterologously expressed and purified in E.coli, respectively. Enzymatic assays of these purified enzymes showed that they all had high affinity for glycolate but with distinct $K_{m}$ values. In addition, GOX3 possesses high catalytic efficiency for L-lactate [22]. In this study, we comparatively investigated enzymatic characteristics of all rice GLO isozymes. GLO1 + 4 showed highest catalytic efficiency using glycolate as substrate, followed by GLO1 and GLO4, respectively (Fig. 2b; Table 1 and Additional file 3). Indeed, the transgenic rice plants that had up-regulated or knocked-out GLO1 or GLO4 exhibited much higher or lower GLO activity, 
Table $1 K_{m}$ of each GLO isozyme with various substrates

\begin{tabular}{lllll}
\hline GLO isozymes & $K_{\text {m(glycolate) }}(\mathrm{mM})$ & $K_{\text {m(glyoxylate) }}(\mathrm{mM})$ & $K_{\text {m(L-lactate) }}(\mathrm{mM})$ & $K_{\text {m(glycerate) }}(\mathrm{mM})$ \\
\hline GLO1 & $0.499 \pm 0.041^{\mathrm{b}}$ & $6.505 \pm 0.412^{\mathrm{a}}$ & $5.128 \pm 0.315^{\mathrm{a}}$ & $4.976 \pm 0.305^{\mathrm{a}}$ \\
GLO3 & $0.470 \pm 0.035^{\mathrm{bc}}$ & $1.799 \pm 0.084^{\mathrm{d}}$ & $1.104 \pm 0.056^{\mathrm{c}}$ & $2.762 \pm 0.311^{\mathrm{c}}$ \\
GLO4 & $0.613 \pm 0.050^{\mathrm{a}}$ & $5.983 \pm 0.333^{\mathrm{b}}$ & $4.720 \pm 0.291^{\mathrm{b}}$ & $4.367 \pm 0.395^{\mathrm{b}}$ \\
GLO1 +4 & $0.423 \pm 0.038^{\mathrm{c}}$ & $4.883 \pm 0.321^{\mathrm{c}}$ & $5.227 \pm 0.448^{\mathrm{a}}$ & $4.511 \pm 0.307^{\mathrm{b}}$ \\
\hline
\end{tabular}

Values are means \pm SD of three replicates. Means denoted by the same letter did not significantly differ at $P<0.05$ according to Duncan's multiple range tests

respectively. Our previous studies also observed that the phenotypes were altered in the GLO1 and GLO4 upregulated or down-regulated transgenic lines $[4,5]$. In contrast, there were no changes in the GLO activity and phenotypes in GLO3 and GLO5 up-regulated or RNAi rice lines (Fig. 3a; Fig 4). In addition, the GLO isozymes zymogram analysis further supported that the GLO isozymes in rice leaves consisted of GLO1 and GLO4 subunits (Fig. 3b and c), and GLO1 was more abundant than GLO4 in rice leaves (Fig. 3b). In combination with our previous results [24], it can be concluded that GLO1, GLO4 and GLO1 + 4 are the GLO isozymes for photorespiration in rice. In addition, this study further revealed that GLO1 + 4 and GLO1 have higher catalytic efficiency on glycolate-oxidation than GLO4 (Fig. 2a and b; Table 1). Therefore it can be further implied that GLO1 could be the major contributor to GLO activity and consequently to photorespiration and the associated $\mathrm{H}_{2} \mathrm{O}_{2}$ production.

GLO3 is the rice homolog of Arabidopsis GOX3. It was recently reported that GOX3 in Arabidopsis functions as an L-lactate oxidase catalyzing the conversion of L-lactate to pyruvate, in order to maintain low levels of L-lactate in roots under normoxic conditions [22]. We observed that the rice GLO3 was also able to efficiently catalyze the oxidation of L-lactate to pyruvate (Fig. 2b; Table 1). Our previous results have demonstrated that GLO3 is predominantly expressed in roots [15, 24], but unexpectedly no GLO activities could be detected in wild type rice roots (Additional file 7). We further noticed that the GLO3 overexpression rice plants conferred no improved resistance to L-lactate toxicity (Additional file 6). This was inconsistent with the Arabidopsis GOX3 overexpression plants which were shown to be more tolerant to L-lactate toxicity [22]. As a semi-aquatic plant,

Table $2 K_{i}$ of GLO with oxalate

\begin{tabular}{lll}
\hline GLO isozymes & $\begin{array}{l}K_{\text {i(oxalate) }}(\mathrm{mM}) \\
\text { Glycolate as substrate }\end{array}$ & $\begin{array}{l}K_{\text {i(oxalate) }}(\mathrm{mM}) \\
\text { Glyoxylate as substrate }\end{array}$ \\
\hline GLO1 & $4.572 \pm 0.930^{\mathrm{c}}$ & $1.887 \pm 0.326^{\mathrm{c}}$ \\
$\mathrm{GLO3}$ & $5.604 \pm 1.229^{\mathrm{b}}$ & $3.018 \pm 1.359^{\mathrm{a}}$ \\
$\mathrm{GLO}$ & $2.272 \pm 0.524^{\mathrm{b}}$ \\
GLO1 +4 & $6.337 \pm 1.736^{\mathrm{a}}$ & $2.316 \pm 0.608^{\mathrm{b}}$ \\
\hline
\end{tabular}

Values are means \pm SD of three replicates. Means denoted by the same letter did not significantly differ at $P<0.05$ according to Duncan's multiple range tests rice produces low lactate as compared with wheat, potato and Arabidopsis [35-38], which might explain why GLO3 is not associated with lactate toxicity in rice as reported for Arabidopsis [22].

While the primary metabolic role of GLO is well known, the physiological function is still not well understood. Rojas et al. (2012) suggested that each GLO isozyme played different roles in the non-host disease resistance in Arabidopsis [16]. A more recent study demonstrated that the Arabidopsis GOX1 and GOX2 played distinct roles in the oxidative stress-related cell death [23]. GLO has also been reported to be involved in some other biological processes such as protein repair responses and salicylic acid signaling pathway [39, 40]. More interestingly, recent studies found that there was cross-talk between photorespiratory $\mathrm{H}_{2} \mathrm{O}_{2}$ and auxin [41, 42]. We found that GLO activity was closely related to $\mathrm{H}_{2} \mathrm{O}_{2}$ levels in rice leaves (Additional file 5), and, as such, the dwarfism phenotype of the GLO downregulated rice lines could be a morphological aberration related to auxin signaling $[43,44]$. Nevertheless, our previous work demonstrated that suppression of GLO may cause accumulation of glyoxylate that inhibits photosynthesis [5], so it is also possible that the dwarfism phenotype results from inhibited photosynthesis. Therefore, each GLO isozyme may exhibit different physiological functions in these various biological processes in rice, but more direct experimental evidence is needed to elucidate the potential mechanisms.

\section{Conclusions}

Our findings suggested that rice GLO isozymes have distinct enzymatic characteristics and different physiological functions. GLO1, GLO4 and GLO1 + 4 are the photorespiration GLO isozymes, moreover, GLO1 is the major contributor to GLO activity and the related photorespiratory $\mathrm{H}_{2} \mathrm{O}_{2}$ production. In addition, there may be interplay between the photorespiration glycolate- $\mathrm{H}_{2} \mathrm{O}_{2}$ metabolism and plant development. However, the certain functions of GLO3 and GLO5 remain to be fully elucidated.

\section{Methods}

Plant materials and growth conditions

The seeds of rice (Oryza sativa) cv. Zhonghua 11 (japonica cultivar-group) provided by the state key 


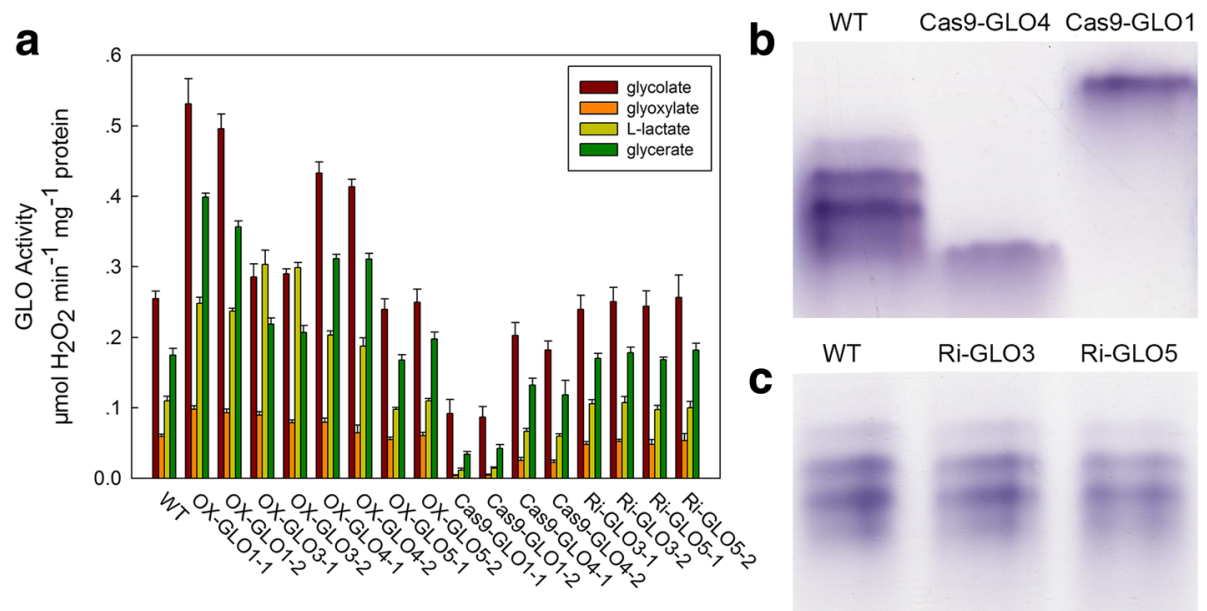

Fig. 3 Catalytic characteristics and isozyme patterns of GLO in vivo. a GLO enzyme activities in different transgenic plants. OX-GLO1, OX-GLO3, OX-GLO4 and OX-GLO5 represent the GLO1, GLO3, GLO4 and GLO5 overexpression transgenic plants, respectively. Cas9-GLO1 and Cas9-GLO4 represent the GLO1 and GLO4 knockout plants, respectively. Ri-GLO3 and Ri-GLO5 represent the specific GLO3 and GLO5 RNA-silencing transgenic plants, respectively. b The GLO isozyme bands of WT, Cas9-GLO4 and Cas9-GLO1 plants. c The GLO isozyme bands of WT, Ri-GLO3 and Ri-GLO5 plants. The second leaf from the top was detached from plants at 4-leaf stage for determination. Values are means \pm SD $(n=3)$

laboratory for conservation and utilization of subtropical agro-bioresources were used for the construction of transgenic lines. Rice seeds were germinated in the dark for 4-6 days at $25{ }^{\circ} \mathrm{C}$, and then the seedlings were grown in Kimura B complete nutrient solution [45] in plant growth chambers with $14 \mathrm{~h}$ light $\left(30{ }^{\circ} \mathrm{C}\right)$ $/ 10 \mathrm{~h}$ dark $\left(25{ }^{\circ} \mathrm{C}\right), 800 \mu \mathrm{mol} \mathrm{m} \mathrm{m}^{-2} \mathrm{~s}^{-1}$ average light intensity, and $60-70 \%$ relative humidity. After reaching the 4-leaf stage, seedlings were transplanted, either being continuously grown in Kimura B complete nutrient solution in the plant growth chambers, or grown in soil under natural condition. The seedlings grown in Kimura B complete nutrient solution in plant growth chambers were exposed to

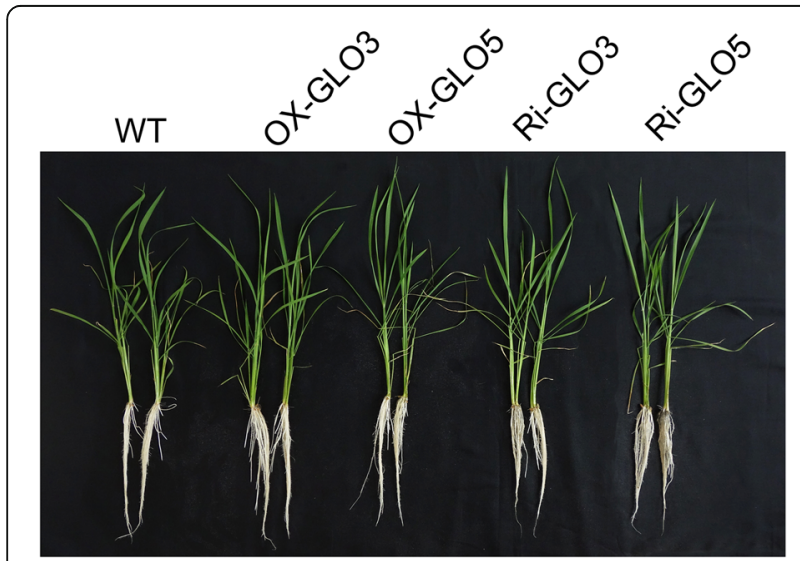

Fig. 4 Growth phenotypes of the GLO3 and GLO5 up- or downregulated transgenic plants. OX-GLO3; OX-GLO5 represent the GLO3 and GLO5 overexpression transgenic plants, respectively; Ri-GLO3 and Ri-GLO5 represent the specific GLO3 and GLO5 RNA-silencing transgenic plants, respectively. The results are representative of three independent experiments various stress treatments (PEG 6000, 10\%; $\mathrm{NaCl}, 100 \mathrm{mM}$; ABA, $\left.10 \mu \mathrm{M} ; \mathrm{H}_{2} \mathrm{O}_{2}, 5 \mathrm{mM} ; \mathrm{AlCl}_{3}, 2 \mathrm{mM}\right)$. The seedlings grown in soil under natural condition were used for GLO isozyme zymogram and growth phenotype analyses.

\section{Plasmid construction}

Total RNA was extracted from rice leaves using RNAprep Pure Kit (TIANGEN, China). The quality and quantity of the purified RNA were assessed with a NanoDrop-1000 (NanoDrop, USA). First-strand cDNA was synthesized using ReverTra Ace (Toyobo, Japan). Primers were designed to cover the complete open reading frame of each GLO gene (Additional file 8). To construct the vectors for protein expression in yeast, a $6 \times$ His-tag was fused to the N-terminus of GLO1, GLO3 and GLO4 [23], and then these modified sequences (NHisGLO1, NHisGLO3 and NHisGLO4) were cloned into pYES3 and pYES2 vectors. To generate GLO-overexpression transgenic lines, each GLO sequence was cloned into pYLox.5 vector. To generate GLO-silencing transgenic lines, primers were designed to amplify the interfering fragment to guarantee the specificity of the silencing (Additional file 8), each specific fragment was then cloned into the RNAi vector pYLRNAi.5. To generate CRISPR-Cas9 knockout lines, specific targeting sequences were synthesized and cloned into pYLCRISPR/Cas9P ubi vector (Additional file 4) [46]. (pYLox.5, pYLRNAi.5 and pYLCRISPR/Cas9 vectors were kindly provided by Dr. Yao-Guang Liu, College of Life Sciences, South China Agricultural University).

\section{Protein expression in Saccharomyces cerevisiae}

The constructed GLO expression vectors were trans-

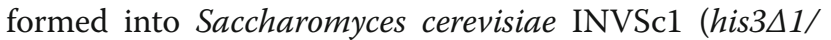


his341 leu2/leu2 trp1-289/trp1-289 ura3-52/ura3-52, Invitrogen) using the lithium acetate/carrier DNA method [47]. After that, yeast cells transformed with GLO constructs were maintained in the SC selective plates (SC-Dropout Medium without Trp/Ura) with 2\% glucose, at $30{ }^{\circ} \mathrm{C}$ for $3-4$ days to isolate the positive clones. The proteins were inductively expressed in S.cerevisiae as previously described [24, 48] with some modifications. Briefly, positive clones were transferred to $10 \mathrm{~mL} \mathrm{SC}$ selective medium containing $2 \%$ glucose, and incubated at $30{ }^{\circ} \mathrm{C}$ for $16 \mathrm{~h}$ with shaking at $250 \mathrm{rpm}$. Appropriate volumes of the culture were transferred to $50 \mathrm{~mL} \mathrm{SC}$ inductive culture medium (SC selective medium containing $2 \%$ galactose) to obtain an OD600 of 0.4 , and then shaken at $30{ }^{\circ} \mathrm{C}$ with $250 \mathrm{rpm}$ for $24 \mathrm{~h}$. Cells were harvested by centrifuging the culture at $5000 \mathrm{rpm}$ for $5 \mathrm{~min}$ at $4{ }^{\circ} \mathrm{C}$, the cell pellets were collected and stored at $-75^{\circ} \mathrm{C}$ until ready to use.

\section{Western blot analysis}

Proteins were extracted from yeast cells using acidwashed glass beads as described previously [48]. Supernatant of the yeast cells extract was collected and used for SDS polyacrylamide gel (SDS-PAGE) electrophoresis. Protein samples separated on 10\% SDS-PAGE were electroblotted onto a nitrocellulose membrane using wet transfer $[49,50]$. GLO was detected using a GLO-antibody. The anti-GLO primary antibody was generated in rabbits by immunization with GLO1 proteins, and this antibody was able to recognize all the rice GLO polypeptides due to the high similarity between these polypeptides.

\section{Purification of active GLO from yeast cells}

Supernatant of the yeast cell lysate was filtered through a $0.45 \mu \mathrm{m}$ membrane for subsequent purification. The Ni-IDA resin (Bio-Rad) was packed in a Bio-Scale MT5 column $(10 \times 64 \mathrm{~mm})$ for bed volumes up to $2 \mathrm{~mL}$, equilibrate the column with 5 column volumes $(\mathrm{CV})$ of wash buffer (50 mM PBS, pH 8.0, $10 \mathrm{mM}$ imidazole, $300 \mathrm{mM} \mathrm{NaCl}$ ). The filtered supernatant were prepared by mixing them with an equal volume of binding buffer (100 mM PBS, pH 8.0, $20 \mathrm{mM}$ imidazole, $600 \mathrm{mM}$ $\mathrm{NaCl}$ ), and then loading them onto the Ni-IDA resin column. The column was washed with $10 \mathrm{CV}$ of wash

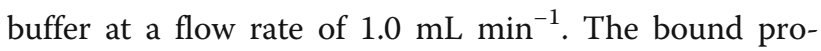
teins were eluted with $5 \mathrm{CV}$ of $50 \mathrm{mM}$ PBS (pH 8.0) containing $150 \mathrm{mM}$ imidazole and $300 \mathrm{mM} \mathrm{NaCl}$. The eluted fractions were desalted by ultrafiltration and checked by $10 \%$ SDS-PAGE. All the purified enzymes were stored in $50 \mathrm{mM}$ PBS ( $\mathrm{pH} 8.0)$ containing $0.1 \mathrm{mM}$ FMN and $10 \%$ glycerol at $-75^{\circ} \mathrm{C}$ for subsequent assay.

\section{GLO isozyme zymogram analysis}

To identify GLO isozymes a Caps-ammonium Clear Native-PAGE system (CN-PAGE) with a running pH of
10.2 was used [51]. The separation gel concentration is $6 \%$, the electrophoresis was performed at $100 \mathrm{~V}$ for $9 \mathrm{~h}$ at $4{ }^{\circ} \mathrm{C}$. Activity staining was carried out by incubating the gel at $30{ }^{\circ} \mathrm{C}$ for $20 \mathrm{~min}$ in a staining solution which contained $\quad 0.016 \% \quad(W / V) \quad \mathrm{NBT}, \quad 0.003 \% \quad(W / V)$ PMS,0.1 mM FMN,10 mM glycolate (pH 6-8), and $50 \mathrm{mM}$ PBS (pH 8.0).

\section{GLO activity assay}

GLO catalytic activity was measured in an enzymecoupled assay according to Hall et al. (1985) unless specific variations were needed in different kinetic and characterization investigations [52]. The typical reaction mixture containing $50 \mathrm{mM}$ PBS (pH 7.8), 5 units of horseradish peroxidase, $1 \mathrm{mM}$ 4-amino-antipyrine, $2 \mathrm{mM}$ phenol, $0.1 \mathrm{mM}$ FMN and $10 \mathrm{mM}$ substrate. The reaction was started by adding the enzyme, distilled water was substituted for substrate as the blank. Formation of $\mathrm{H}_{2} \mathrm{O}_{2}$ produced in the reaction which reflects the catalytic activity of GLO was monitored spectrophotometrically at $520 \mathrm{~nm}$ under $30^{\circ} \mathrm{C}$.

The effects of varying $\mathrm{pH}$ were assayed with two buffers: $\mathrm{pH}$ of $50 \mathrm{mM}$ PBS from 6 to 8 , and $50 \mathrm{mM}$ Tris- $\mathrm{HCl}$ from 8 to 9 . As for the effects of temperature, the reaction mixtures were pre-incubated at various temperatures $\left(22-60{ }^{\circ} \mathrm{C}\right.$ ) for $5 \mathrm{~min}$, and then the GLO activities were measured at the same temperature.

For kinetic parameter determination, oxidations of the substrate were performed over a range of concentration (0.1-0.8 $\mathrm{mM}$ for glycolate, $1.0-8.0 \mathrm{mM}$ for glyoxylate, $0.5-6.0 \mathrm{mM}$ for L-lactate, $0.5-6.0 \mathrm{mM}$ for glycerate), the $K_{m}$ was calculated from double-reciprocal plots according to the method of Lineweaver and Burk, moreover, slopes of the reciprocal plots were then plotted against the concentration of oxalate (range 1.0-8.0 mM), to evaluate $K_{i}$ data [53].

\section{Generation of GLO transgenic line}

The constructed vectors were introduced into rice by Agobacterium-mediated infection (strain EHA105) [54]. The seeds from the positive T0 lines were germinated in complete Kimura B nutrient solution and then transplanted to soil. The T2 or T3 plants were used for the determination of GLO activity and the Real-time quantitative PCR (qRT-PCR) assay. Besides, the T3 plants of GLO3-transgenic lines were used for lactate toxicity test (L-lactate, $2.0 \mathrm{mM}$ ).

\section{Real-time quantitative PCR}

The specific primer pairs were designed for the qRT-PCR of each GLO gene (Additional file 8). Total RNA was purified from rice using TRIzol $^{\circ}$ reagent (Life Technologies, Carlsbad, USA), and further treated with DNase I (RNase free, Toyobo, Osaka, Japan). The quality of the isolated 
RNA was assessed with a NanoDrop-1000 (Thermo Fisher Scientific, Bremen, Germany). One microgram of RNA was used as a template for first-strand cDNA synthesis using ReverTra Ace (Toyobo, Osaka, Japan). The qRT-PCR reaction mixture consisted of $0.2 \mu \mathrm{M}$ (each) primer, $10 \mu \mathrm{L}$ of $2 \times$ SYBR Green PCR Master Mix (Toyobo, Osaka, Japan), and $2 \mu \mathrm{L}$ of appropriate diluted cDNA. The analysis was conducted using a DNA Engine Opticon 2 Real-Time PCR Detection system and Opticon Monitor software (Bio-Rad, Hercules, CA). The data were normalized to the amplification of the OsActin1 gene (Os03g0718100).

\section{3, 3'-diaminobenzidine staining}

The leaf $\mathrm{H}_{2} \mathrm{O}_{2}$ abundance was estimated by the 3, 3'-diaminobenzidine (DAB) uptake method [55]. The youngest fully expanded leaves of the five-leaf stage rice were detached $(10 \mathrm{~cm})$, and the cut end was dipped into $4 \mathrm{~mL}$ of DAB solution $\left(1 \mathrm{mg} \mathrm{mL}^{-1}, \mathrm{pH} 3.8\right)$ for $2 \mathrm{~h}$ in light at $30{ }^{\circ} \mathrm{C}$. The experiment was terminated by boiling the leaves in ethanol for $30 \mathrm{~min}$.

\section{Quantification of proteins}

The protein content was determined according to Bradford (1976) with bovine serum albumin as a standard [56], and the experiments were repeated three times with at least three replicates for each sample.

\section{Additional files}

Additional file 1: Similarities of rice GLO gene members at the level of mRNA and protein. (DOCX $16 \mathrm{~kb}$ )

Additional file 2: (a) Effect of varying pH on activities of GLO isozymes. Each buffer $(50 \mathrm{mM})$ was made of respective PBS (pH 6.0-8.0) and Tris- $\mathrm{HCl}$ (pH 8.0-9.0). (The highest activity of each GLO isozyme at pH 7.8 was set as 1). (b) Effect of temperature on activities of GLO isozymes. Enzymes in $50 \mathrm{mM}$ PBS buffer $(\mathrm{pH} 7.8)$ were pre-incubated at various temperatures $\left(22-60^{\circ} \mathrm{C}\right)$ for $5 \mathrm{~min}$, and then activities were measured at the same temperature (For GLO1 and GLO1 + 4, the highest activity at $45^{\circ} \mathrm{C}$ was set as 1; For GLO3, the highest activity at $47^{\circ} \mathrm{C}$ was set as 1 ; For GLO4, the highest activity at $42^{\circ} \mathrm{C}$ was set as 1). Values are means \pm SD $(n=3)$. (TIFF $7340 \mathrm{~kb})$

Additional file 3: The $V_{\max }$ of purified GLO isozymes with various substrates. (DOCX $18 \mathrm{~kb}$ )

Additional file 4: (a) Relative mRNA levels were graphed based on the GLO1 mRNA level in WT leaves as 1. (b) Relative MRNA levels were graphed based on the GLO4 mRNA level in WT leaves as 1. (c) Mutation of GLO1 and GLO4 knockout lines generated by pYLCRISPR/Cas9P ubi system. (d) Relative mRNA levels were graphed based on the GLO3 mRNA level in WT leaves as 1. (e) Relative mRNA levels were graphed based on the GLO5 mRNA level in WT leaves as 1. Values are means \pm SD $(n=3)$. (TIFF $5131 \mathrm{~kb})$

Additional file 5: $\mathrm{H}_{2} \mathrm{O}_{2}-3,3^{\prime}$-diaminobenzidine (DAB) staining in rice leaves. Cas9-GLO1 and Cas9-GLO4 represent the GLO1 and GLO4 knockout plants, respectively. The result is representative of three independent experiments. (TIFF $10179 \mathrm{~kb}$ )

Additional file 6: L-lactate toxicity test in GLO3 transgenic plants. Different transgenic rice lines (4-leaf stage) were grown in Kimura B complete nutrient solution containing $2.0 \mathrm{mM}$ L-lactate for one week. OX-GLO3 and Ri-GLO3 represent the GLO3 overexpression transgenic plants and the specific GLO3 RNA-silencing transgenic plants, respectively. The results are representative of three independent experiments. (TIFF $7069 \mathrm{~kb}$ )
Additional file 7: GLO activity in root of GLO3 over expression plants. (DOCX $17 \mathrm{~kb}$ )

Additional file 8: The primers used for the plasmid construction and real-time quantitative PCR. (DOCX $18 \mathrm{~kb}$ )

\section{Abbreviations}

2-PG: Phosphoglycolate; CN-PAGE: Clear-native polyacrylamide gel electrophoresis; DAB: 3, 3'-diaminobenzidine; FMN: Flavin mononucleotide; GLO: Glycolate oxidase; PGP: 2-PG phosphatase; qRT-PCR: Real-time quantitative PCR

\section{Acknowledgements \\ None.}

\section{Funding}

This work was supported in part by the National Natural Science Foundation of China (Grant Nos. 31,600,193 and 31,470,343) and the Hunan Provincia Natural Science Foundation of China (Grant No. 2017JJ3109). The funders had no role in study design, data collection and analysis, decision to publish, or preparation of the manuscript.

\section{Availability of data and materials}

All data generated or analysed during this study are included in this published article [and its supplementary information files].

\section{Authors' contributions}

PXX conceived the study, edited the manuscript and supervised the work. ZZS carried out most analyses, contributed to the design of the study and drafted the manuscript. LXY prepared protein samples for analysis, prepared the rice seeds, grew rice plants and performed stress treatment. CLL performed the qRT-PCR analysis. MS and YNH drafted and revised the manuscript. All authors read and approved the final manuscript.

Ethics approval and consent to participate Not applicable.

\section{Consent for publication}

Not applicable.

\section{Competing interests}

The authors declare that they have no competing interests.

\section{Publisher's Note}

Springer Nature remains neutral with regard to jurisdictional claims in published maps and institutional affiliations.

\section{Author details}

${ }^{1}$ Southern Regional Collaborative Innovation Center for Grain and Oil Crops in China, Hunan Agricultural University, Changsha, Hunan 410128, China. ${ }^{2}$ State Key Laboratory for Conservation and Utilization of Subtropical Agro-bioresources, College of Life Sciences, South China Agricultural University, Guangzhou, Guangdong 510642, China.

Received: 20 March 2017 Accepted: 23 July 2017

Published online: 08 August 2017

References

1. Richardson KE, Tolbert NE. Oxidation of glyoxylic acid to oxalic acid by glycolic acid oxidase. J Biol Chem. 1961;236:1280-4.

2. Macheroux P, Massey V, Thiele DJ, Volokita M. Expression of spinach glycolate oxidase in Saccharomyces cerevisiae: purification and characterization. Biochemistry. 1991;30:4612-9.

3. Foyer $\mathrm{CH}$, Bloom AJ, Queval G, Noctor G. Photorespiratory metabolism. Genes, mutants, Energetics, and Redox signaling. Annu Rev Plant Biol. 2009;60:455-84

4. Cui L, Lu Y, Li Y, Yang C, Peng X. Overexpression of Glycolate Oxidase confers improved photosynthesis under high light and high temperature in Rice. Front Plant Sci. 2016;7:1165. 
5. Lu Y, Li Y, Yang Q, Zhang Z, Chen Y, Zhang S, Peng X. Suppression of glycolate oxidase causes glyoxylate accumulation that inhibits photosynthesis through deactivating Rubisco in rice. Physiol Plant. 2014;150:463-76.

6. Mittler R, Zilinskas BA. Regulation of pea cytosolic ascorbate peroxidase and other antioxidant enzymes during the progression of drought stress and following recovery from drought. Plant J. 1994:5:397-405.

7. Rizhsky L, Liang $H$, Mittler R. The combined effect of drought stress and heat shock on gene expression in tobacco. Plant Physiol. 2002;130:1143-51.

8. Mukherjee SP, Choudhuri MA. Implications of water stress-induced changes in the levels of endogenous ascorbic acid and hydrogen peroxide in Vigna seedlings. Physiol Plant. 1983;58:166-70.

9. Bohman S, Wang M, Dixelius C. Arabidopsis thaliana-derived resistance against Leptosphaeria maculans in a Brassica napus genomic background. Theor Appl Genet. 2002;105:498-504.

10. Taler D, Galperin M, Benjamin I, Cohen Y, Kenigsbuch D. Plant eR genes that encode photorespiratory enzymes confer resistance against disease. Plant Cell. 2004;16:172-84.

11. Schafer $\mathrm{P}$, Huckelhoven $\mathrm{R}$, Kogel $\mathrm{KH}$. The white barley mutant albostrians shows a supersusceptible but symptomless interaction phenotype with the hemibiotrophic fungus Bipolaris sorokiniana. Mol Plant-Microbe Interact. 2004:17:366-73.

12. Peterhansel C, Horst I, Niessen M, Blume C, Kebeish R, Kürkcüoglu S, Kreuzaler F. Photorespiration. Arabidopsis Book. 2010;8:e130

13. Noctor $\mathrm{G}$. Drought and oxidative load in the leaves of $\mathrm{C} 3$ plants: a predominant role for photorespiration? Ann Bot. 2002;89:841-50.

14. Corpas FJ, Barroso JB, Del Río LA. Peroxisomes as a source of reactive oxygen species and nitric oxide signal molecules in plant cells. Trends Plant Sci. 2001;6:145-50

15. Xu H, Zhang J, Zeng J, Jiang L, Liu E. Inducible antisense suppression of glycolate oxidase reveals its strong regulation over photosynthesis in rice. J Exp Bot. 2009; 60:1799-809.

16. Rojas CM, Senthil-Kumar M, Wang K, Ryu CM, Kaundal A, Mysore KS. Glycolate Oxidase modulates reactive oxygen species-mediated signal transduction during nonhost resistance in Nicotiana benthamiana and Arabidopsis. Plant Cell. 2012;24:336-52.

17. Popov VN, Dmitrieva EA, Eprintsev AT, Igamberdiev AU. Glycolate oxidase isoforms are distributed between the bundle sheath and mesophyll tissues of maize leaves. J Plant Physiol. 2003;160:851-7.

18. Havir EA. Evidence for the presence in tobacco leaves of multiple enzymes for the oxidation of glycolate and glyoxylate. Plant Physiol. 1983:71:874-8.

19. Lindqvist Y. Refined structure of spinach glycolate oxidase at $2 \AA$ resolution. J Mol Biol. 1989;209:151-66.

20. Kamada T, Nito K, Hayashi H, Mano S, Hayashi M, Nishimura M. Functional differentiation of Peroxisomes revealed by expression profiles of Peroxisomal genes in Arabidopsis thaliana. Plant Cell Physiol. 2003;44:1275-89.

21. Yamagami T, Tsuchisaka A, Yamada K, Haddon WF, Harden LA, Theologis A. Biochemical diversity among the 1-amino-cyclopropane-1-carboxylate synthase isozymes encoded by the Arabidopsis gene family. J Biol Chem. 2004:278:49102-12.

22. Engqvist MK, Schmitz J, Gertzmann A, Florian A, Jaspert N, Arif M, Balazadeh S, Mueller-Roeber B, Fernie AR, Maurino VG. GLYCOLATE OXIDASE3, a Glycolate OXIDASE homolog of yeast L-lactate Cytochrome c Oxidoreductase, supports L-lactate oxidation in roots of Arabidopsis. Plant Physiol. 2015;169:1042-61.

23. Kerchev PI, Waszczak C, Lewandowska A, Willems P, Shapiguzov A, Li Z, Alseekh S, Mühlenbock P, Hoebrichts F, Huang JJ, Van Der Kelen K, Kangasjärvi J, Fernie AR, De Smet R, Van de Peer Y, Messens J, Van Breusegem F. Lack of GLYCOLATE OXIDASE 1, but not GLYCOLATE OXIDASE 2, attenuates the photorespiratory phenotype of CATALASE2-deficient Arabidopsis. Plant Physiol. 2016;171:1704-19.

24. Zhang Z, Lu Y, Zhai L, Deng R, Jiang J, Li Y, He Z, Peng X. Glycolate oxidase isozymes are coordinately controlled by GLO1 and GLO4 in rice. PLoS One. 2012;7:e39658.

25. Gräslund S, Nordlund P, Weigelt J, Bray J, Gileadi O, Knapp S. Protein production and purification. Nat Methods. 2008:5:135-46.

26. Franceschi VR, Nakata PA. Calcium oxalate in plants: formation and function. Annu Rev Plant Biol. 2005;56:41-71.

27. Nishimura M, Akhmedov YD, Strzalka K, Akazawa T. Purification and characterization of glycolate oxidase from pumpkin cotyledons. Arch Biochem Biophys. 1983;222:397-402.

28. Odanaka S, Bennett AB, Kanayama Y. Distinct physiological roles of fructokinase isozymes revealed by gene-specific suppression of Frk1 and Frk2 expression in tomato. Plant Physiol. 2002;129:1119-26.
29. Frigerio NA, Harbury HA. Preparation and some properties of crystalline glycolic acid oxidase of spinach. J Biol Chem. 1958;231:135-57.

30. Zelitch I, Ochoa S. Oxidation and reduction of glycolic and glyoxylic acids in plants I. Glycolic acid oxidase. J Biol Chem. 1953;201:707-18.

31. Cederlund $E$, Lindqvist $Y$, Söderlund $G$, Brändén $C l$, Jörnvall $H$. Primary structure of glycolate oxidase from spinach. Eur J Biochem. 1988;173:523-7.

32. Macheroux P, Mulrooney SB, Williams CJ, Massey V. Direct expression of active spinach glycolate oxidase in Escherichia coli. Biochim Biophys Acta. 1992;1132:11-6.

33. Devi MT, Rajagopalan AV, Raghavendara AS. Purification and properties of glycolate oxidase from plants with different photosynthetic pathways: distinctness of C4 enzyme from that of a C3 species and a C3-C4 intermediate. Photosynth Res. 1996;47:231-8.

34. Reumann S. Specification of the Peroxisome targeting signals type 1 and type 2 of plant Peroxisomes by bioinformatics analyses. Plant Physiol. 2004;135:783-800.

35. Sweetlove LJ, Dunford R, Ratcliffe RG, Kruger NJ. Lactate metabolism in potato tubers deficient in lactate dehydrogenase activity. Plant Cell Environ. 2000;23:873-81

36. Mustroph A, Jr BG, Kaiser KA, Larive CK, Bailey-Serres J. Characterization of distinct root and shoot responses to low-oxygen stress in Arabidopsis with a focus on primary C- and N-metabolism. Plant Cell Environ. 2014:37:2366-80.

37. Menegus F, Cattaruzza L, Mattana M, Beffagna N, Ragg E. Response to anoxia in rice and wheat seedlings changes in the $\mathrm{pH}$ of intracellular compartments, glucose-6-phosphate level, and metabolic rate. Plant Physiol. 1991;95:760-7.

38. Menegus F, Cattaruzza L, Chersi A, Fronza G. Differences in the anaerobic lactate-succinate production and in the changes of cell sap pH for plants with high and low resistance to anoxia. Plant Physiol. 1989;90:29-32.

39. Sewelam N, Jaspert N, Van Der Kelen K, Tognetti VB, Schmitz J, Frerigmann H, Stahl E, Zeier J, Van Breusegem F, Maurino VG. Spatial $\mathrm{H}_{2} \mathrm{O}_{2}$ signaling specificity: $\mathrm{H}_{2} \mathrm{O}_{2}$ from chloroplasts and peroxisomes modulates the plant transcriptome differentially. Mol Plant. 2014;7:1191-210.

40. Zhang Z, Xu Y, Xie Z, Li X, He Z, Peng X. Association-dissociation of Glycolate Oxidase with Catalase in Rice: a potential switch to modulate intracellular $\mathrm{H}_{2} \mathrm{O}_{2}$ levels. Mol Plant. 2016;9:737-48.

41. Kerchev P, Muhlenbock P, Denecker J, Morreel K, Hoeberichts FA, Kelen KVD Vandorpe $\mathrm{M}$, Long N, Audenaert D, Breusegem FV. Activation of auxin signaling counteracts photorespiratory $\mathrm{H}_{2} \mathrm{O}_{2}$ dependent cell death. Plant Cell Environ. 2013;38:253-65.

42. Gao X, Hong M, Hu Y, Li J, Lu Y. Mutation of Arabidopsis CATALASE2 results in hyponastic leaves by changes of auxin levels. Plant Cell Environ. 2014;37:175-88.

43. Zhang S, Li C, Jia C, Zhang Y, Zhang S, Xia Y, Sun D, Ying S. Altered architecture and enhanced drought tolerance in rice via the down-regulation of indole-3acetic acid by TLD1/OsGH3.13 activation. Plant Physiol. 2009;151:1889-901.

44. Zhao S, Xiang J, Xue H. Studies on the Rice LEAF INCLINATION1 (LC1), an IAA-amido Synthetase, reveal the effects of Auxin in leaf INCLINATION control. Mol Plant. 2013;6:174-87.

45. Yoshida S, Forno DA, Cock JH, Gomez KA. Laboratory manual for physiological studies of rice. Manila: International Rice Research Institute; 1976.

46. Ma X, Zhang Q, Zhu Q, Wei L, Yan C, Rong Q, Wang B, Yang Z, Li H, Lin Y. A robust CRISPR/Cas9 system for convenient, high-efficiency multiplex genome editing in monocot and dicot plants. Mol Plant. 2015:8:1274-84.

47. Schiestl RH, Gietz RD. High efficiency transformation of intact yeast cells using single stranded nucleic acids as a carrier. Curr Genet. 1989;16:339-46.

48. Zhang Z, Mao X, Ou J, Ye N, Zhang J, Peng X. Distinct photorespiratory reactions are preferentially catalyzed by glutamate:glyoxylate and serine: glyoxylate aminotransferases in rice. J Photochem Photobiol B. 2015;142:110-7.

49. Towbin H, Staehelin T, Gordon J. Electrophoretic transfer of proteins from polyacrylamide gels to nitrocellulose sheets: procedure and some applications. Proc Natl Acad Sci U S A. 1979;76:4350-4.

50. Laemmli UK. Cleavage of structural proteins during the assembly of the head of bacteriophage T4. Nature. 1970;227:680-5.

51. McLellan T. Electrophoresis buffers for polyacrylamide gels at various $\mathrm{pH}$. Anal Biochem. 1982;126:94-9.

52. Hall NP, Reggiani R, Lea PJ. Molecular weights of glycollate oxidase from C3 and $\mathrm{C} 4$ plants determined during early stages of purification. Phytochemistry. 1985;24:1645-8

53. Lineweaver H, Burk D. The determination of enzyme dissociation constants. J Am Chem Soc. 1934;56:658-66.

54. Hiei Y, Ohta S, Komari T, Kumashiro T. Efficient transformation of rice (Oryza sativa L.) mediated by Agrobacterium and sequence analysis of the boundaries of the T-DNA. Plant J. 1994;6:271-82. 
55. Thordal Christensen $\mathrm{H}$, Zhang Z, Wei $\mathrm{Y}$, Collinge DB. Subcellular localization of $\mathrm{H}_{2} \mathrm{O}_{2}$ in plants. $\mathrm{H}_{2} \mathrm{O}_{2}$ accumulation in papillae and hypersensitive response during the barley-powdery mildew interaction. Plant J. 1997;11:1187-94.

56. Bradford MM. A rapid and sensitive method for the quantitation of microgram quantities of protein utilizing the principle of protein-dye binding. Anal Biochem. $1976 ; 72: 248-54$.

Submit your next manuscript to BioMed Central and we will help you at every step:

- We accept pre-submission inquiries

- Our selector tool helps you to find the most relevant journal

- We provide round the clock customer support

- Convenient online submission

- Thorough peer review

- Inclusion in PubMed and all major indexing services

- Maximum visibility for your research

Submit your manuscript at www.biomedcentral.com/submit 